\title{
Kissing nevus of the penis. Report of two cases and review of the literature*
}

Songting Wang ${ }^{1}$

Mingshu Zhou

Jianjun Qiao³

\section{DOI: http://dx.doi.org/10.1590/abd1806-4841.20142870}

Abstract: Kissing nevus is a curious type of nevus that was first described on the eyelids and rarely described on the penis. We report two cases of kissing nevus of the penis and review previously reported cases. The lesions of the kissing nevus of the penis showed characteristic mirror-image symmetry relative to the coronal sulcus. On histopathology, the lesion showed a compound nevus.

Keywords: Melanocytes; Nevus, pigmented; Penis

\section{INTRODUCTION}

Kissing nevus, also known as divided nevus, is a curious type of nevus that was first described on the eyelids and only rarely described on the penis. It is defined as two adjacent melanocytic nevi that involve those parts of the body that split at some point during embryogenesis. ${ }^{1}$ To date, only 13 cases of kissing nevus of the penis have been reported. Here we report two new cases and review the published cases.

\section{CASE REPORT}

\section{Case 1}

A 23-year-old man presented with two pigmented lesions on his penis since the time when the prepuce could be retracted, in his teens. Physical examination revealed two sharply marginated pigmented patches on the inner surface of the prepuce and on the dorsolateral side of the penis respectively (Figure 1). The two lesions appeared as mirror images of each other relative to the coronal sulcus when the prepuce was retracted. The coronal sulcus was exempt from pigmentation. His family and past history was negative. Histological examination of the biopsy specimen taken from the prepuce revealed a compound nevus with no sign of malignancy (Figure 2). The patient refused any treatment for the lesions and started a follow-up.

\section{Case 2}

A 26-year old man presented with two asymptomatic black lesions on the penis that were seen from the time when the prepuce could be retracted, in his teens. On physical examination, two hyperpigmented patches were located on the dorsal glans penis and the prepuce respectively (Figure 3). The two patches overlapped each other when the prepuce was retracted. The patient refused further treatment.

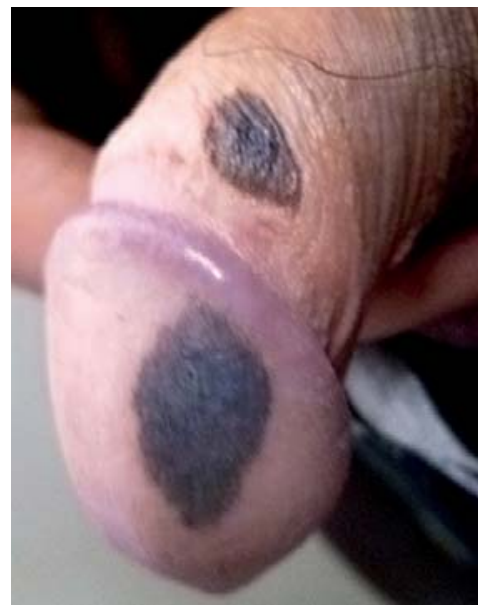

FIGURE 1:

Case 1: Sharply marginated pigmented patches on the glans penis and on the inner surface of the prepuce at the dorsolateral side of the penis appeared as mirror images of each other relative to the coronal sulcus

Received on 16.06.2013.

Approved by the Advisory Board and accepted for publication on 29.07.2013.

* Work performed at the Department of Dermatology, The First Affiliated Hospital, College of Medicine, Zhejiang University - Hangzhou, China. Financial Support: None

Conflict of Interests: None.

Beilun People's Hospital, Ningbo - Zhejiang, China.

Shandong Institute of Parasitic diseases, and The Third Affiliated Hospital, Shandong Academy of Medical Science- Shandong, China

The First Affiliated Hospital, College of Medicine, Zhejiang University - Hangzhou, China. 


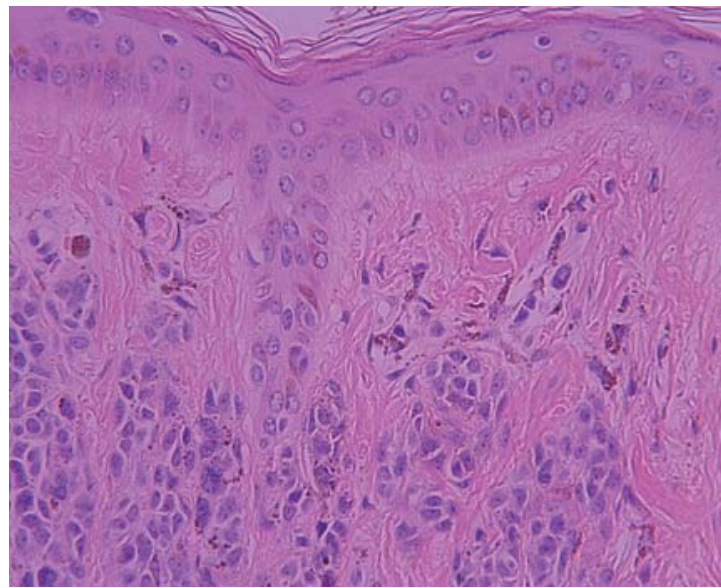

FIGURE 2: Histology of a biopsy taken from the prepuce of case 1 showed a compound nevus with no sign of malignancy (haematoxylin and eosin; original magnification $\times 400$ )

\section{DISCUSSION}

In this paper, we report two cases of kissing nevus of the penis. Kissing nevus of the eyelids was first described in 1908 and more than 40 cases have been reported. Other types and locations of kissing nevus have been rarely reported. These nevi include divided epidermal nevus of the finger, mast cell nevus, nevus spilus of the eyelids, and kissing nevus of the penis. ${ }^{2}$ The first case of kissing nevus of the penis was reported in 1998. To our knowledge, 13 cases of kissing nevus of the penis have been described in English literature (Table 1). ${ }^{1-9}$

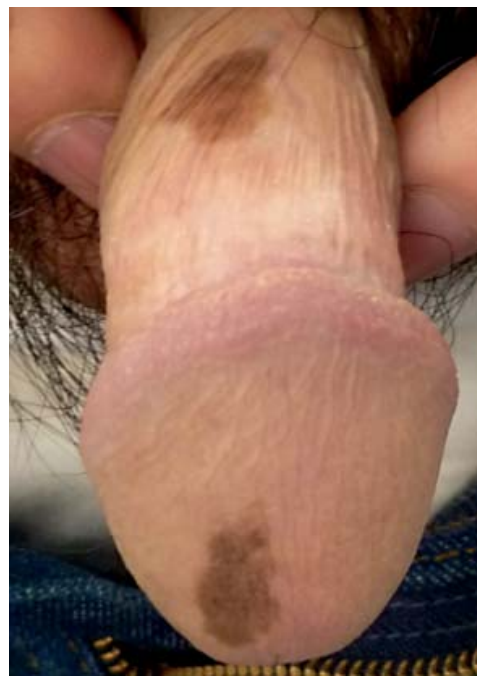

Figure 3

Case 2: Two hyperpigmented patches were located on the dorsal glans penis and the prepuce respectively. The patches overlapped each other when the prepuce was retracted
In all of the 15 reported cases (including the current two cases) the nevi were located on the dorsal or dorsolateral side of the glans and the inner face of the prepuce, without involving the coronal sulcus. Most lesions presented as sharply-demarcated, smooth-surfaced, oval-shaped, and pigmented patches. They showed mirror-image symmetry relative to the coronal sulcus. On histopathology they were mostly demonstrated as intradermal or compound melanocytic nevi.

Cleavage of the invaginated epithelial preputial placode severs and forms the glans and the prepuce

Table 1: Published cases of kissing nevus of the penis

\begin{tabular}{|c|c|c|c|c|}
\hline Reference & Age & Onset age & Treatment & Malignant \\
\hline \multicolumn{5}{|l|}{ transformation } \\
\hline Present report & 23 & Teens & Close observation & No \\
\hline Present report & 26 & Teens & Close observation & No \\
\hline Yun, et al. ${ }^{2}$ & 27 & 17 & Close observation & No \\
\hline Zhou, et al. ${ }^{3}$ & 21 & 7 & Close observation & No \\
\hline Zhou, et al. ${ }^{3}$ & 25 & teens & Close observation & No \\
\hline Zhou, et al. ${ }^{3}$ & 20 & NR & Close observation & No \\
\hline Higashida, et al. ${ }^{5}$ & 11 & 8 & Total excision and skin graft: good result & No \\
\hline Palmer, et al. ${ }^{4}$ & 6 & 6 & Laser treatment: good result & No \\
\hline Egberts, et al. ${ }^{6}$ & 30 & 30 & Total excision and skin graft: good result & Yes \\
\hline Phan, et al. ${ }^{7}$ & 14 & 13 & Total excision: good result & No \\
\hline Kono, et al. ${ }^{8}$ & 12 & 1 & $\mathrm{NR}$ & No \\
\hline Kono, et al. ${ }^{8}$ & 21 & NR & NR & No \\
\hline Kono, et al. ${ }^{8}$ & 9 & NR & NR & No \\
\hline Choi, et al. ${ }^{9}$ & 18 & NR & NR & No \\
\hline Desruelles, et al. ${ }^{1}$ & 7 & 3 & NR & No \\
\hline
\end{tabular}

$\mathrm{NR}=$ not reported 
during the $11-14^{\text {th }}$ gestational week. ${ }^{1,8}$ It has been hypothesized that melanoblasts migrate to the lesion before the embryological separation of epithelial preputial placode, just following the completion of the preputial epithelial placode invagination at the 12th gestation week. ${ }^{1,8}$ Consequently, the melanoblasts divide at this location when the epithelial separation between the prepuce and glans begins at opposite sites by the $13^{\text {th }}$ gestational week. ${ }^{1,8}$ This embryological disjunction explains why all kissing nevus of the penis have a mirror-image appearance relative to the coronal sulcus. The predilection site of the lesions is almost always the dorsal or dorsolateral aspect, which may be explained by the fact that epithelial invagination from the dorsal side precedes the ventral side.

The focus of the therapy for a kissing nevus of the penis should be on functional and esthetic outcome. It has been reported that surgical resection and

\section{REFERENCES}

1. Desruelles F, Lacour JP, Mantoux F, Ortonne JP. Divided nevus of the penis: an unusual location. Arch Dermatol. 1998;134:879-80.

2. Yun SJ, Wi HS, Lee JB, Kim SJ, Won YH, Lee SC. Kissing nevus of the penis. Ann Dermatol. 2011;23:512-4.

3. Zhou C, Xu H, Zang D, Du J, Zhang J. Divided nevus of the penis. Eur J Dermatol. 2010;20:527-8.

4. Palmer B, Hemphill M, Wootton C, Foshee JB, Frimberger D. Kissing nevus discovered at circumcision consult. J Pediatr Urol. 2010;6:318-9.

5. Higashida $Y$, Nagano T, Oka M, Nishigori C. Divided naevus of the penis. Acta Derm Venereol. 2010;90:319.

6. Egberts F, Egberts JH, Schwarz T, Hauschild A. Kissing melanoma or kissing nevus of the penis? Urology. 2007;69:384.e5-7.

7. Phan PT, Francis N, Madden N, Bunker CB. Kissing naevus of the penis. Clin Exp Dermatol. 2004;29:471-2.

8. Kono T, Nozaki M, Kikuchi Y, Erçöçen AR, Hayashi N, Chan HH, et al. Divided naevus of the penis: a hypothesis on the embryological mechanism of its development. Acta Derm Venereol. 2003;83:155-6.

9. Choi GS, Won DH, Lee SJ, Lee JH, Kim YG. Divided naevus on the penis. Br J Dermatol. 2000;143:1126-7.

10. Fernandes NC. The risk of cutaneous melanoma in melanocytic nevi. An Bras Dermatol. 2013;88:314-5. reconstruction by skin grafting using remnant foreskin achieved satisfactory outcomes. ${ }^{5}$ However, for large lesions, surgical resection may lead to scar and deform the glans penis. Laser has been used for the treatment of kissing nevus of the eyelids and showed favorable esthetic results. Therefore we postulate laser therapy may result in good satisfactory outcome for treating kissing nevus of the penis.

Although rare, a malignant transformation of a kissing nevus might take place both in the eyelids and the penis..$^{10}$ Only one case of malignant transformation of kissing nevus of the penis has been reported. ${ }^{6}$ Therefore patients with kissing nevus should be given a close follow-up.

In summary we report two cases of kissing nevus of the penis and review the cases published in the literature. All the lesions show characteristic mirror-image symmetry relative to the coronal sulcus.

\author{
MAILING ADDRESS: \\ Jianjun Qiao \\ No. 79, Qingchun Road \\ Hangzhou, 310003 \\ Zhejiang Province, People's Republic of China. \\ E-mail: qiaojianjun@zju.edu.cn
}

How to cite this article: Wang S, Zhou M, Qiao J. Kissing nevus of the penis. Report of two cases and review of the literature. An Bras Dermatol. 2014;89(2)329-31. 